\title{
Survivin expression in oral squamous cell carcinoma
}

\section{Lo Muzio*,', G Pannone², S Staibano ${ }^{2}$, MD Mignogna ${ }^{3}$, C Rubini ${ }^{4}$, MA Mariggiò ${ }^{5}$, M Procaccini', F Ferrari', G De Rosa ${ }^{2}$ and DC Altieri}

'Institute of Dental Sciences, Faculty of Medicine, University of Ancona, Ancona, Italy; ${ }^{2}$ Department of Biomorphological and Functional Sciences, Pathology Unit, Faculty of Medicine, University of Naples Federico II, Naples, Italy; ${ }^{3}$ Department of Dental Sciences, Faculty of Medicine, University of Naples Federico II, Naples, Italy; ${ }^{4}$ Institute of Pathology, University of Ancona, Ancona, Italy; ${ }^{5}$ Department of Biomedical Sciences and Human Oncology Section of General Pathology and Experimental Oncology, University of Bari, Bari, Italy; ${ }^{6}$ Department of Cancer Bioilogy and the Cancer Center, University of Massachusetts Medical School, Worcester, MA OI 605, USA

A series of I 10 cases of oral squamous cell carcinoma (SCC) together with six lymph node and one distant metastatic lesions was analysed for expression of survivin, a recent apoptosis inhibitor, by immunohistochemistry and Western blotting. In total, 9 I cases (82.7\%) of carcinoma and all metastasis (seven cases, 100\%) were positive for survivin expression, with weighted survivin scores ranging from I to 4 . In contrast, normal oral epithelium did not express survivin. There was no significant correlation between survivin expression and age, sex, tumour size, the presence of lymph node and distant metastases. Survivin expression was increased in poorly differentiated tumours, even if differences were not statistically significant. In contrast, when analysed for prognostic significance, patients with low survivin expression had statistically significant better survival rates than the group with high survivin expression $(P<0.05)$. These data suggest that survivin expression may identify cases of oral SCC with more aggressive and invasive phenotype. British Journal of Cancer (2003) 89, 2244-2248. doi:I0.1038/sj.bjc.660I402 www.bjcancer.com

(c) 2003 Cancer Research UK

Keywords: survivin; squamous cell carcinoma; oral mucosa; mouth; apoptosis

The frequency of squamous cell carcinoma (SCC) of the oral mucosa (OSCC) is rapidly increasing. In particular, OSCC constitutes the most frequent malignant tumour of the oral cavity. The incidence of metastasis depends on the degree of cellular differentiation, deep invasion, and site of the primary tumour. However, the clinical behaviour of the single cases of tumours is difficult to predict basing on classical histopathological parameters alone. Biological markers that can identify the lesions with more aggressive phenotype and worse prognosis still need to be identified.

Carcinogenesis is a multistage process involving the activation of oncogenes and the inactivation of tumour suppressor genes. In this context, most human tumours are characterised by an imbalance of regulatory mechanisms controlling cell cycle progression, cell death/viability balance, and apoptosis.

Apoptosis has become a basic tool in developing cancer research and establishing new cancer strategies. Apoptosis, or programmed cell death, is a genetically controlled process, which maintains developmental morphogenesis (Vaux et al, 1994), and homeostasis of differentiated organisms by removing senescent, unneeded, or dangerous cells (Sternberg, 1997). Aberrations of this process leading to aberrantly reduced cell death are thought to participate in cancer by promoting increased resistance to therapy and favouring the insurgence of transforming mutations (Jameson, 1998).

* Correspondence: Prof L Lo Muzio, Institute of Dental Sciences, Faculty of Medicine, University of Ancona, Via Carelli 28, 7II 00 Foggia, Italy; E-mail: Ilomuzio@tin.it

Revised 5 September 2003; accepted 16 September 2003
Considerable interest has recently focused on the identification of regulators of apoptosis, which may potentially influence the cell death/cell viability balance in cancer. In addition to pro- and antiapoptotic bcl-2 molecules (Reed, 1998), a second gene family of inhibitor of apoptosis (IAP) has been recently identified (Crook et al, 1993). Highly evolutionarily conserved from viruses to mammalian cells (Crook et al, 1993; Ambrosini et al, 1997), IAP proteins target a downstream step in apoptosis by inhibiting the terminal effector caspase-3 and -7 (Deveraux et al, 1997; Tamm et al, 1998), and by interfering with processing/activation of the pinnacle caspase, caspase-9.

Previous studies demonstrated that expression of antiapoptotic bcl-2 in oral SCC could potentially contribute to tumour progression. This was suggested by the increased expression of bcl-2 protein and mRNA in poorly differentiated oral SCCs as compared with histological normal oral epithelium (Chen et al, 2000).

Survivin is a recently characterised IAP protein, which is abundantly expressed in most solid and haematological malignancies, but undetectable in normal adult tissues (Ambrosini et al, 1997). Interference with survivin function induces pleiotropic celldivision defects and apoptosis ( $\mathrm{Li}$ et al, 1999), suggesting a potential role at the interface between cell division and apoptosis control. In retrospective trials, survivin expression correlated with unfavourable neuroblastoma (Adida et al, 1998a), reduced overall survival in primitive colorectal (Kawasaki et al, 1998) and recurrent colorectal cancer (Sarela et al, 2000), non-small-cell lung cancer (Monzo et al, 1999), breast cancer (Tanaka et al, 2000), and increased rates of recurrences in bladder cancer (Swana et al, 1999). Consistent with a critical role of apoptosis inhibition in tumour progression, overexpression of survivin in model cancer 
cell types provided a broad cytoprotective mechanism, counteracting apoptosis induced by FAS/TNF legation, proapoptotic Bax, effector caspases, and various chemotherapeutic drugs (Tamm et al, 1998).

In this study, we sought to investigate the potential expression and impact of survivin protein in oral SCC. We found that survivin is expressed in about $80 \%$ of oral SCC, and that its degree of expression correlates with a more aggressive phenotype.

\section{MATERIALS AND METHODS}

\section{Selection of cases}

A total of 110 samples from paraffined and 10 from frozen specimens of primary oral SCC, seven from paraffined specimens of lymph node (six cases) and tissue metastases (one case) of OSCCs included in this study were used. Specimens were fixed in $10 \%$ neutral-buffered formalin.

None of the patients had been treated previously. They received surgical treatment with curative intention. No case in this study concerned patients with contemporaneous multicentric lesions. Clinical data was reviewed to record sex and age of the patient, and site and size of the lesion. The group consisted of 80 men and 30 women with a mean age of 59.6 years (range $39-78$ ). There were 38 stage I, 29 stage II, 14 stage III, and 29 stage IV. Only 76 patients were analysed for survival rates (the follow-up time was sufficient for statistical analysis, $>3$ years). Survival was calculated from the date of operation to the date of the latest follow-up visit or death due to cancer. Patients who died of postoperative complications within 30 days were excluded. The histopathological grading was assessed on paraffin haematoxylin-eosin (H\&E)-stained sections. Tumour extent was classified according to the TNM system by UICC (UICC, 1987), and tumours were divided into grades 1,2 , and 3 using the WHO classification of histological differentiation.

In all, 10 paraffined and five frozen specimens of healthy oral mucosa were obtained from patients who had undergone routine oral surgical procedures (such as impacted third molars, metaprotesic reactive epithelial hyperplasia, etc.) with the informed consent of the donors. The use of archived human tissues conformed to an informed consent protocol that had been reviewed and approved by the institutional review board of the University of Naples Federico II, Italy.

\section{Immunohistochemistry}

Serial sections $(4 \mu \mathrm{m})$ from formalin-fixed, paraffin-embedded blocks were cut for each case, and one section stained with $\mathrm{H} \& \mathrm{E}$ was used to confirm the histopathological diagnosis. Only sections containing sufficient epithelium to assess the antibody reactivity with 1000 cells were considered for this study.

Immunohystochemistry was then performed on the remaining sections mounted on poly-L-lysine-coated glass slides. Immunohistochemical staining was carried out with a rabbit polyclonal antibody supplied by NOVUS (NOVUS Biologicals, Littleton, CO, USA) raised against full-length recombinant survivin characterised in previous studies (Grossman et al, 1999a; Grossman et al, 2001), using the standard streptavidin-biotin-peroxidase complex technique using the Dako LSAB kit (DAKO A/S, Carpinteria, CA, USA) after antigen retrieval by pressure cooking. Briefly, deparaffined sections were immersed in a $10^{-3} \mathrm{M}$ sodium citrate buffer ( $\mathrm{pH}$ 6.0) after bringing the solution to a boil in a pressure cooker, and then heated two times for $3 \mathrm{~min}$ each at a $10-\mathrm{min}$ interval while keeping the pressure indicator valve rising. After quenching in 3\% hydrogen peroxide and blocking, the sections were incubated with primary antibody diluted $1: 50$ overnight at $4^{\circ} \mathrm{C}$. Biotinylated anti-rabbit immunoglobulin and streptavidin conjugated to horseradish peroxidase were subsequently applied. Finally, 3,3'-diaminobenzidine was used for colour development, and haematoxylin was used for counterstaining. Negative control slides in the absence of primary antibody were included for each staining.

The results of the immunohistochemical staining were evaluated separately by two observers, blind to the histologic diagnosis of the single cases and especially to the follow-up data for the respective patients.

To quantitate the survivin expression, 300 cells were examined in at least five areas at $\times 400$ magnification and a mean percentage of positive tumour cells was determined assigning cases to one of the five following categories: (a) $0,<5 \%$; (b) $1,5-25 \%$; (c) $2,26-$ $50 \%$; (d) 3, 51-75\%; and (e) 4, >75\%. Cases with score of 0 were considered as negative, cases with scores of 1-4 as positive.

\section{Statistical analysis}

Data were analysed using Prism (ver 3.0 for windows) and Stanton A. Glantz (ver 3.0 for dos) softwares. Significant differences $(P<0.05)$ between groups were determined using nonparametric Comparisons Test (Kruskall - Wallis test) and Mann - Whitney test and also $\chi^{2}$ test. Survival analysis was computed comparing negative (score 0) and low expressing (score 1) with medium (score 2-3) and high (score 4) expressing survivin. Survival curves were analysed according to the method of Kaplan-Meier, and for differences between curves the $P$-value was calculated by the logrank test. A $P$-value of less than 0.05 was accepted as statistically significant.

\section{Western blot analysis}

Frozen tissues from five samples of oral mucosa and 10 from oral SCCs were homogenised directly into lysis buffer containing $50 \mathrm{~mm}$ HEPES, $150 \mathrm{~mm} \mathrm{NaCl}, 1 \mathrm{~mm}$ EDTA, 1 mM EGTA, 10\% glycerol, $1 \%$ Triton-X-100 (1:2 weight/volume), $1 \mathrm{~mm}$ phenylmethylsulphonyl fluoride (PMSF), $1 \mu \mathrm{g}$ aprotinin, $0.5 \mathrm{~mm}$ sodium orthovanadate, $20 \mathrm{~mm}$ sodium pyrophosphate (Sigma Chemical Co, St Louis, MO, USA), and clarified by centrifugation at $14000 \times 10 \mathrm{~min}$. Protein concentrations were estimated using a modified Bradford assay (Bio-Rad, Melville, NY, USA).

In all, $50 \mu \mathrm{g}$ of total protein extracts was boiled in Laemmli buffer for $5 \mathrm{~min}$ before electrophoresis. The samples were subjected to SDS-PAGE (14\% polyacrylamide) under reducing conditions. After electrophoresis, proteins were transferred to nitrocellulose membrane (Immobilon Millipore Corporation, Bedford, MA, USA); complete transfer was assessed using prestained protein standards (Bio-Rad, Melville, NY, USA). The membranes were treated for $2 \mathrm{~h}$ with blocking solution $(5 \%$ no fat powdered milk in $25 \mathrm{~mm}$ Tris, $\mathrm{pH} 7.4 ; 200 \mathrm{~mm} \mathrm{NaCl} ; 0.5 \%$ Triton X-100, TBS/ $\mathrm{T}$ ), and then the membranes were incubated for $12 \mathrm{~h}$ at $4{ }^{\circ} \mathrm{C}$ with the primary antibody against survivin. After washing with TBS/T and TBS, membranes were incubated with the horseradish peroxidase-conjugated secondary antibody $(1: 5000)$ for $1 \mathrm{~h}$ (at room temperature) and the reaction was detected with enhanced chemiluminescence (ECL) system (Amersham Life Science, UK).

After stripping, membranes were incubated with a monoclonal antibody against beta-actin 1:5000 for $1 \mathrm{~h}$ at room temperature (Sigma-Aldrich, St. Louis, MO, USA) to ensure an equivalent protein loading in each lane.

\section{RESULTS}

\section{Survivin expression in normal oral mucosa}

Normal oral mucosa specimens showed positivity only in sporadic cells of basal and parabasal layers and were considered negative for 
survivin expression by immunohistochemistry $($ score $=0$ ), in agreement with previous observations (Lo Muzio et al, 2001)

\section{Survivin expression in oral SCC}

Immunohistochemical staining for survivin was observed in 20 $100 \%$ of cancer cells. The immunostaining was prevalently cytoplasmic in poorly differentiated cases with sporadic prominent nuclear staining in well-differentiated areas, as already reported in cervical mucosa (Frost et al, 2002). However, in this study, differences in the intracellular pattern of staining that resulted were not statistically significant; for this reason, we recorded the specimens as positive without considering the intracellular localisation of the signal (cytoplasmic or nuclear). In contrast, neighbouring normal tissues did not express survivin. After survivin score, 91 cases $(82.7 \%)$ of oral mucosa cancers were defined as positive, with weighted survivin scores ranging from 1 to 4 (Figures 1A-D). Expression of $\sim 16.5 \mathrm{kDa}$ survivin in tissue extracts of oral SCC was also demonstrated by Western blotting (Figure 2). All the cases of metastasis enclosed in this study showed survivin positivity.

There was no significant correlation between survivin expression and age, sex, tumour size, or the presence of lymph node and distant metastases (Table 1). Survivin expression was often

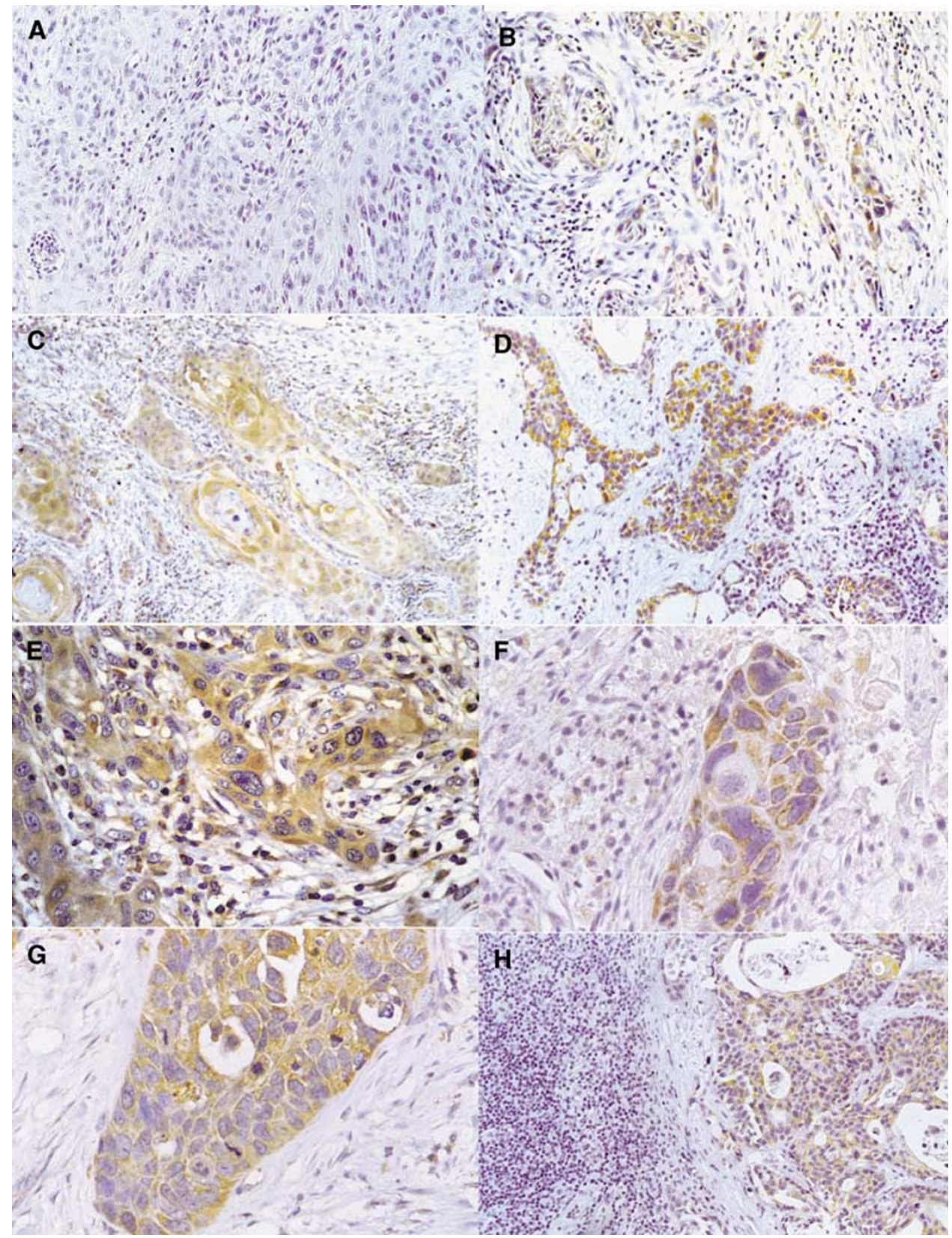

Figure I (A) A case of moderate-differentiated oral SCC showing no staining for survivin, score $0(A B C, I 50 \times)(B) A$ case of moderate/lowdifferentiated oral SCC showing staining for survivin, score I $(A B C, 106 \times)(\mathbf{C})$ A case of moderate differentiated oral SCC showing prevalent cytoplasmatic staining for survivin, score $2(A B C, 150 \times)$ (D) A case of oral SCC with low grade of differentiation showing cytoplasmatic positivity for survivin, score 4 $(A B C, 106 \times)(\mathbf{E})$ A case of oral SCC with low grade of differentiation showing cytoplasmatic positivity for survivin at high power, score $4(A B C, 250 \times)(\mathbf{F})$ A case of oral SCC with low grade of differentiation showing cytoplasmatic positivity for survivin at high power, score 4 (ABC, $400 \times)(\mathbf{G}) A$ case of oral SCC with low grade of differentiation showing cytoplasmatic positivity for survivin at high power, score $4(A B C, 400 \times)(\mathbf{H})$ A case of lymph node metastasis from oral SCC with definite immunostaining for survivin in tumor cells (ABC, $106 \times$ ). 
increased in poor differentiated tumours, but differences that resulted were not statistically significant. In contrast, when analysed for prognostic significance, patients with low survivin expression had better survival rates than the group with medium and high survivin expression (Figure 3 ). This difference of survival rates was statistically significant $(P<0.05)$ and the Hazard was 0.2696 with $95 \%$ confidence interval ranging from 0.02666 to 0.85475 .

\section{DISCUSSION}

In this study, we have shown that a novel antiapoptosis gene, survivin, is prominently expressed in more than $80 \%$ of oral SCC. In particular, survivin expression often increased in poorly differentiated tumours, even if differences were not statistically significant. Of more interest, the high survivin expression that resulted correlated with poor survival rates.

Compelling experimental evidence recently suggested that deregulation of apoptosis plays a critical role in the onset and progression of cancer (Thompson, 1995). This conclusion

A

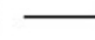

B

$$
42 \mathrm{kDa}
$$

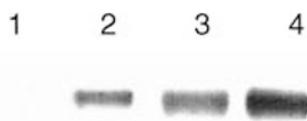

Figure 2 (A) Western blot detection of survivin protein in the tissue extracts of normal mucosa (lane I), well-differentiated SCC (lanes 2), and poorly differentiated SCC (lanes 3 and 4). Proteins (50 $\mu \mathrm{g} / \mathrm{lane}$ ) was resolved by SDS-PAGE, transferred to nitrocellulose membrane and then incubated with antibody raised against survivin. A specific band was observed sizing about $16.5 \mathrm{kDa}$ by comparison with comigrating size markers (Bio-Rad, Melville, NY, USA). (B)The same membrane was stripped and incubated with antibody raised against beta-actin, sizing about $42 \mathrm{kDa}$ (Sigma-Aldrich). The blots are representative of three separate assays.

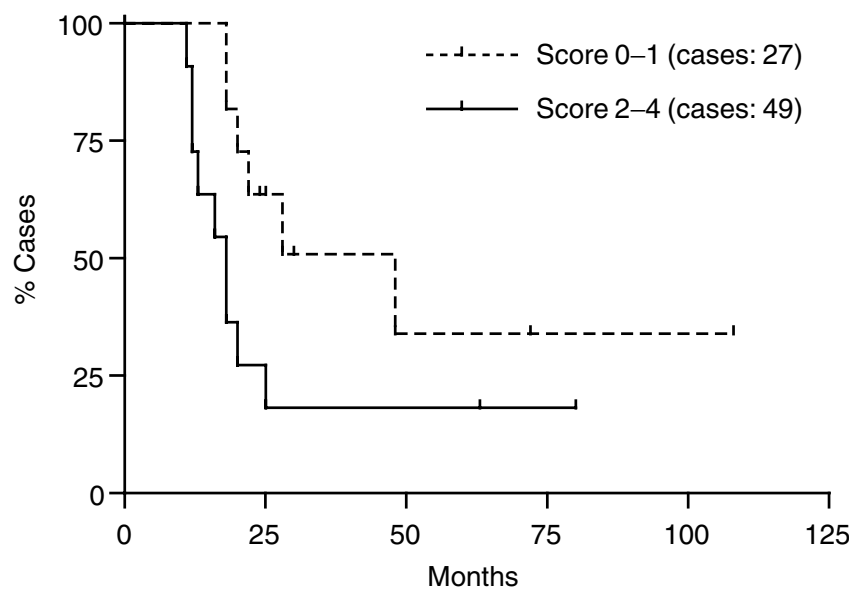

Figure 3 Survival analysis was computed comparing low expressing (score $0-1$ ) with medium/high (score $2-4$ ) expressing survivin. Patients with negative or low score had better survival rates than patients with medium and high score for survivin expression. This difference of survival rates was statistically significant $(P<0.05)$

stemmed primarily from the effects of deregulated bcl-2 expression in follicular lymphoma, which resulted in aberrantly prolonged Bcell survival, increased accumulation of transforming mutations, and accelerated transition to more aggressive and therapy-resistant disease (Hua et al, 1988). A similar paradigm has also been suggested for other solid malignancies, thus prompting the search for additional molecular markers potentially influencing the cell death/cell viability balance in cancer. In this context, recent studies identified the IAP family protein, survivin, as a novel apoptosis inhibitor selectively overexpressed in most human cancers, but not in normal tissues (Ambrosini et al, 1997; Adida et al, 1998b). Differently from bcl-2 family molecules, IAP proteins are thought to block a highly evolutionarily conserved step in cell death by binding and inhibiting terminal effector caspases-3 and -7 (Deveraux et al, 1998), thus providing a separate and nonredundant pathway of cell viability in cancer.

Table I Statistical analysis of survivin score expression and associated clinicopathological findings in oral SCCs

\begin{tabular}{|c|c|c|c|c|c|c|c|c|c|c|c|}
\hline Variables & No. & $\begin{array}{c}\text { Survivin expression } \\
\text { n. (\%) }\end{array}$ & $\begin{array}{l}\text { Score } 0 \\
\text { no. (\%) }\end{array}$ & $\begin{array}{l}\text { Score I } \\
\text { no. (\%) }\end{array}$ & $\begin{array}{l}\text { Score } 2 \\
\text { no. }(\%)\end{array}$ & $\begin{array}{l}\text { Score } 3 \\
\text { no. (\%) }\end{array}$ & $\begin{array}{l}\text { Score } 4 \\
\text { no. (\%) }\end{array}$ & Mean & S.d. & S.e. & $\mathbf{P}$ \\
\hline Cases & 110 & 91 (82.7) & $19(17.2)$ & $16(14.5)$ & $27(24.5)$ & $24(21.8)$ & $24(21.8)$ & & & & \\
\hline \multicolumn{12}{|l|}{ Age } \\
\hline$<60$ years & 36 & $30(83)$ & $6(5.4)$ & $5(4.5)$ & II (10) & $9(8.1)$ & $5(4.5)$ & 2.056 & 1.286 & 0.214 & \\
\hline$>60$ years & 74 & $61(82)$ & $13(1 \mid .8)$ & II (10) & $16(14.5)$ & $15(13.6)$ & $19(17.2)$ & 2.216 & 1.436 & 0.166 & $0.5310^{\mathrm{a}}$ \\
\hline \multicolumn{12}{|l|}{ Sex } \\
\hline Male & 80 & $66(82)$ & $14(12.7)$ & II (10) & $19(17.2)$ & $18(16.3)$ & $18(16.3)$ & 2.188 & 1.397 & 0.1562 & $0.7521^{a}$ \\
\hline Female & 30 & $25(83)$ & $5(4.5)$ & $5(4.5)$ & $8(7.2)$ & $6(5.4)$ & $6(5.4)$ & 2.100 & 1.373 & 0.2507 & \\
\hline \multicolumn{12}{|l|}{ Grading } \\
\hline Gl & 23 & $18(78)$ & $5(5)$ & $2(1.8)$ & $4(3.6)$ & $5(4.5)$ & $7(6.3)$ & 2.304 & 1.550 & 0.3232 & \\
\hline G2 & 62 & $51(82)$ & II (10) & $12(10.9)$ & $18(16.3)$ & $10(9)$ & II (10) & 1.968 & 1.342 & 0.1705 & $0.1787^{b}$ \\
\hline G3 & 25 & $22(88)$ & $3(2.7)$ & $2(1.8)$ & $5(4.5)$ & $9(8.1)$ & $6(5.4)$ & 2.520 & 1.295 & 0.2590 & \\
\hline \multicolumn{12}{|l|}{ Size $(\mathrm{cm})$} \\
\hline$<1.5$ & 36 & $30(83)$ & $6(5.4)$ & $3(2.7)$ & II (10) & $8(7.2)$ & $8(7.2)$ & 2.250 & 1.360 & 0.226 & $0.6684^{a}$ \\
\hline$>1.5$ & 74 & $61(82)$ & $13(1 \mid .8)$ & $13(11.8)$ & $16(14.5)$ & $16(14.5)$ & $16(14.5)$ & 2.122 & 1.404 & 0.163 & \\
\hline \multicolumn{12}{|l|}{$\begin{array}{l}\text { Lymph node metastasis } \\
\text { Negative }\end{array}$} \\
\hline Positive $(\mathrm{N}+)$ & 68 & $57(83)$ & II (10) & $10(9)$ & $18(16.3)$ & $14(12.7)$ & $15(13.6)$ & 2.176 & $1.37 \mid$ & 0.1662 & $0.9361^{a}$ \\
\hline Lymph node metastasis & 42 & $34(80)$ & $8(7.2)$ & $6(5.4)$ & $9(8.1)$ & $10(9)$ & $9(8.1)$ & 2.143 & 1.424 & 0.2197 & \\
\hline \multicolumn{12}{|l|}{ Staging } \\
\hline i & 38 & $30(78)$ & $8(7.2)$ & $4(3.6)$ & $10(9)$ & $4(3.6)$ & $12(10.9)$ & 2.211 & 1.527 & 0.2478 & $0.2436^{b}$ \\
\hline$\|$ & 29 & $23(79)$ & $6(5.4)$ & $4(3.6)$ & $8(7.2)$ & $8(7.2)$ & $3(2.7)$ & 1.931 & 1.307 & 0.2428 & \\
\hline III & 14 & $13(92)$ & I (0.9) & I (0.9) & $2(1.8)$ & $6(5.4)$ & $4(3.6)$ & 2.786 & 1.188 & 0.3176 & \\
\hline IV & 29 & $25(86)$ & $4(3.6)$ & $7(6.3)$ & $7(6.3)$ & $6(5.4)$ & $5(4.5)$ & 2.034 & 1.322 & 0.2456 & \\
\hline
\end{tabular}

a Mann-Whitney test. ${ }^{\mathrm{b}}$ Nonparametric comparisons test (Kruskall-Wallis test). 
Here, the presence of survivin in more aggressive and poorly differentiated variants of oral SCC confirms and extends earlier reports of survivin expression in skin cancers (Chiodino et al, 1999; Grossman et al, 1999b), and suggests its potential predictive/ prognostic impact for disease progression. In model cancer cells, expression of the survivin gene was shown to occur exclusively in the $\mathrm{G} 2 / \mathrm{M}$ phase in a strict cell cycle-regulated manner ( $\mathrm{Li}$ et al, 1998), thus potentially explaining a preferential expression of survivin in poorly differentiated and metastatic SCC, likely to exhibit high proliferative potential. At a molecular level, survivin localised to mitotic spindle microtubules of dividing cells ( $\mathrm{Li}$ et al, 1998), in a reaction required to preserve apoptosis inhibition. Moreover, in vitro targeting experiments using survivin antisense or a dominant negative survivin mutant demonstrated that this unique topography was also required for proper cell division timing and cell progression through mitosis. Consistent with this view, RNA interference of a survivin-homologous BIR1 protein in model organisms also resulted in embryonic lethality due to a profound defect of cytokinesis (Fraser et al, 1999). Altogether, these data suggest that survivin expression in aggressive SCC may provide a strong growth advantage factor for tumour progression, affording both protection from broad apoptosis-inducing stimuli/ drugs and maintaining proper mitotic progression of the proliferating population. Consistent with this view, recent studies (Glinsky et al, 1997) demonstrated that highly metastatic cancers exhibit a higher resistance to apoptotic cell death as compared to low-metastatic counterparts (Glinsky et al, 1997).

In summary, these data suggest that survivin expression in oral SCC may identify patients at risk of more aggressive and disseminated disease. This may be relevant for the institution of closer follow-up protocols and/or alternative combined therapeutic regimens. These findings reiterate the importance of deregulation of apoptosis as a critical pathogenetic component of tumour progression, and identify survivin as a potential novel molecular marker of aggressive neoplasia.

\section{ACKNOWLEDGEMENTS}

This investigation was supported in part by NIH Grants CA78810 and CA91917, in part by the Italian Research Program of MIUR year 2002, and by the Research Program of the University of Ancona - year 2001 Studio dell'espressione della proteina antiapoptosica survivin nel carcinoma del cavo orale.

\section{REFERENCES}

Adida C, Berrebi D, Peuchmaur M, Reyes-Mugica M, Altieri DC (1998a) Anti-apoptosis gene, survivin, and prognosis of neuroblastoma. Lancet 351: $882-883$

Adida C, Crotty PL, McGrath J, Berrebi D, Diebold J, Altieri DC (1998b) Developmentally regulated expression of the novel cancer anti-apoptosis gene survivin in human and mouse differentiation. Am J Pathol 152: $43-49$

Ambrosini G, Adida C, Altieri DC (1997) A novel anti-apoptosis gene, survivin, expressed in cancer and lymphoma. Nat Med 3: 917-921

Chen Y, Kayano T, Takagi M (2000) Dysregulated expression of bcl-2 and bax in oral carcinomas: evidence of post-transcriptional control. J Oral Pathol Med 29: 63-69

Chiodino C, Cesinaro AM, Ottani D, Fantini F, Giannetti A, Trentini GP, Pincelli C (1999) Communication: expression of the novel inhibitor of apoptosis survivin in normal and neoplastic skin. J Invest Dermatol 113: $415-418$

Crook NE, Clem RJ, Miller LK (1993) An apoptosis-inhibiting baculovirus gene with a zinc finger-like motif. J Virol 67: 2168-2174

Deveraux QL, Roy N, Stennicke HR, Van Arsdale T, Zhou Q, Srinivasula SM, Alnemri ES, Salvesen GS, Reed JC (1998) IAPs block apoptotic events induced by caspase- 8 and cytochrome $c$ by direct inhibition of distinct caspases. EMBO J 17: 2215-2223

Deveraux QL, Takahashi R, Salvesen GS, Reed JC (1997) X-linked IAP is a direct inhibitor of cell-death proteases. Nature 388: 300-304

Fraser AG, James C, Evan GI, Hengartner MO (1999) Caenorhabditis elegans inhibitor of apoptosis protein (IAP) homologue BIR-1 plays a conserved role in cytokinesis. Curr Biol 9: 292-301

Frost M, Jarboe EA, Orlicky D, Gianani R, Thompson LC, Enomoto T, Shroyer KR (2002) Immunohistochemical localization of survivin in benign cervical mucosa, cervical dysplasia, and invasive squamous cell carcinoma. Am J Clin Pathol 117: 738-744

Glinsky GV, Glinsky VV, Ivanova AB, Hueser CJ (1997) Apoptosis and metastasis: increased apoptosis resistance of metastatic cancer cells is associated with the profound deficiency of apoptosis execution mechanisms. Cancer Lett 115: $185-193$

Grossman D, Kim PJ, Blanc-Brude OP, Brash DE, Tognin S, Marchisio PC, Altieri DC (2001) Transgenic expression of survivin in keratinocytes counteracts UVB-induced apoptosis and cooperates with loss of p53. J Clin Invest 108: 991 - 999

Grossman D, McNiff JM, Li F, Altieri DC (1999a) Expression and targeting of the apoptosis inhibitor, survivin, in human melanoma. J Invest Dermatol 113: $1076-1081$

Grossman D, McNiff JM, Li F, Altieri DC (1999b) Expression of the apoptosis inhibitor, survivin, in nonmelanoma skin cancer and gene targeting in a keratinocyte cell line. Lab Invest 79: 1121-1126
Hua C, Zorn S, Jensen JP, Coupland RW, Ko HS, Wright JJ, Bakhshi A (1988) Consequences of the $t(14 ; 18)$ chromosomal translocation in follicular lymphoma: deregulated expression of a chimeric and mutated BCL-2 gene. Oncogene Res 2: 263-275

Jameson JL. (1998) Principles of Molecular Medicine. Totowa, New Jersey: Humana Press

Kawasaki H, Altieri DC, Lu CD, Toyoda M, Tenjo T, Tanigawa N (1998) Inhibition of apoptosis by survivin predicts shorter survival rates in colorectal cancer. Cancer Res 58: 5071-5074

Li F, Ackermann EJ, Bennett CF, Rothermel AL, Plescia J, Tognin S, Villa A Marchisio PC, Altieri DC (1999) Pleiotropic cell-division defects and apoptosis induced by interference with survivin function. Nat Cell Biol 1: $461-466$

Li F, Ambrosini G, Chu EY, Plescia J, Tognin S, Marchisio PC, Altieri DC (1998) Control of apoptosis and mitotic spindle checkpoint by survivin. Nature 396: $580-584$

Lo Muzio L, Staibano S, Pannone G, Mignogna MD, Mariggio A, Salvatore G, Chieffi P, Tramontano D, De Rosa G, Altieri DC (2001) Expression of the apoptosis inhibitor survivin in aggressive squamous cell carcinoma. Exp Mol Pathol 70: 249-254

Monzo M, Rosell R, Felip E, Astudillo J, Sanchez JJ, Maestre J, Martin C, Font A, Barnadas A, Abad A (1999) A novel anti-apoptosis gene: reexpression of survivin messenger RNA as a prognosis marker in nonsmall-cell lung cancers. J Clin Oncol 17: 2100-2104

Reed JC (1998) Bcl-2 family proteins. Oncogene 17: 3225-3236

Sarela AI, Macadam RC, Farmery SM, Markham AF, Guillou PJ (2000) Expression of the antiapoptosis gene, Survivin, predicts death from recurrent colorectal carcinoma. Gut 46: 645-650

Sternberg SS. (1997) Histology for Pathologist. Philadelphia: LippincottRaven Publishers

Swana HS, Grossman D, Anthony JN, Weiss RM, Altieri DC (1999) Tumor content of the antiapoptosis molecule survivin and recurrence of bladder cancer. $N$ Engl J Med 341: $452-453$

Tamm I, Wang Y, Sausville E, Scudiero DA, Vigna N, Oltersdorf T, Reed JC (1998) IAP-family protein survivin inhibits caspase activity and apoptosis induced by Fas (CD95), Bax, caspases, and anticancer drugs. Cancer Res 58: 5315-5320

Tanaka K, Iwamoto S, Gon G, Nohara T, Iwamoto M, Tanigawa N (2000) Expression of survivin and its relationship to loss of apoptosis in breast carcinomas. Clin Cancer Res 6: $127-134$

Thompson CB (1995) Apoptosis in the pathogenesis and treatment of disease. Science 267: 1456-1462

UICC (1987) TNM Classification of Malignant Tumours. Berlin: Springer:

Vaux DL, Haecker G, Strasser A (1994) An evolutionary perspective apoptosis. Cell 76: $777-779$ 